\title{
LA MORALIDAD DE LA APARIENCIA: BUENAS MANERAS E INCLUSIÓN SOCIAL EN DAVID HUME
}

\author{
Juan Samuel Santos Castro* \\ doi:10.11144/Javeriana.uph33-66.bmis
}

Las buenas maneras son, a las sociedades particulares, lo que la moralidad

es a la sociedad en general, su cemento y su seguridad

Lord Chesterfield ${ }^{1}$

\section{Introducción}

POCOS PONDRÍAN EN DUDA la utilidad de las llamadas buenas maneras o reglas de cortesía. Comúnmente, se dice que son el "lubricante" de las relaciones sociales. Sin embargo, más allá de estudios sociológicos que elaboran esta gráfica descripción, las buenas maneras no constituyen uno de los temas centrales del interés filosófico contemporáneo ${ }^{2}$. Pero esto no siempre fue así. Durante los

* Pontificia Universidad Javeriana, Bogotá, Colombia.

Correo electrónico: juan.santos@javeriana.edu.co

Para citar este artículo: Santos Castro, J.S. (2016). La moralidad de la apariencia. Buenas maneras e inclusión social en David Hume. Universitas Philosophica, 33(66), pp. 265-292 ISSN 0120-5323, ISSN en línea: 2346-2426, doi: 10.11144/ Javeriana.uph33-66.bmis

1 La traducción es mía. La cita original dice: "Good manners are, to particular societies, what good morals are to society in general; their cement and their security". Hay cierta ironía en este epígrafe. Sobre la historia de Lord Chesterfield y la correspondencia a su hijo, ver: Davidson, 2004.

2 No obstante, existen interesantes estudios alrededor de temas cercanos tales como la virtud de la modestia (Ben-Ze'ev, 1993; Dixon, 2005; Driver, 1989; Hill Jr., 1991; Richards, 1988; Schueler, 1997; Woodcock, 2008), las relaciones entre la hipocresía y la politeness, especialmente en el ámbito político (Klein, 1994; Davidson, 2004), y el papel de las formalidades y la civilidad en el mundo contemporáneo (Waldron, 2013). 
siglos XVII y XVIII, las buenas maneras, entendidas mediante el término amplio de "politeness", ocuparon una parte importante del trabajo de varios autores británicos, entre ellos el de David Hume ${ }^{3}$. La razón de este interés, quizás sorpresiva desde nuestra perspectiva contemporánea, fue una profunda preocupación por las tensiones que ciertas desigualdades económicas y políticas provocan en el tejido social. Considerar el pensamiento de estos autores del pasado es una invitación a reflexionar sobre la relación que existe entre la pleitesía que le rendimos a ciertas figuras de autoridad y la justicia de las desigualdades que sostienen tal autoridad. Creo que esta es una reflexión necesaria en el mundo de hoy, especialmente en el contexto de nuestra universidad.

Dividiré mi presentación en tres partes. En la primera, propondré una interpretación de la concepción humeana de la politeness o las buenas maneras. Mi propósito es llamar la atención hacia la idea de la función que las buenas maneras cumplen dentro del ámbito social. Hume deliberadamente ignora la cuestión, para él ingenua, acerca de la sinceridad de las buenas maneras, y en su lugar, se esfuerza por mostrar que ellas son importantes mecanismos de corrección o, al menos, de contención de ciertas desigualdades sociales. Mi tesis es que, para Hume, las buenas maneras constituyen una clase de comportamiento artificialmente inculcado, orientado a mitigar el efecto de algunas pasiones que nos llevan a profundizar las desigualdades generadoras de conflicto entre los miembros de una comunidad. En tal sentido, las buenas maneras son moralmente relevantes porque alivian los efectos de la injusticia y de la opresión. Después de defender esta interpretación, señalaré algunos aspectos problemáticos del argumento de Hume, poniéndolo en contraste con las opiniones corrientes acerca de las buenas maneras de algunos de sus contemporáneos. A mi juicio, hay algunas moralejas que se pueden extraer de esta discusión para la comprensión de la cortesía en el trabajo intelectual y académico en general. Por ello, finalmente, en la tercera parte indicaré algunas lecciones útiles del debate sobre las buenas maneras para nuestra práctica de la filosofía y de la historia de la filosofía.

3 Sobre el interés característico de la modernidad británica en la cultura de la politeness, ver: Davidson, 2004. 


\section{Orgullo, modestia y buenas maneras}

En la Europa ilustrada de los siglos XVII y XVIII, la extensión de la politeness o buenas maneras no estaba claramente delimitada (Davidson, 2004). En diferentes círculos, el término polite servía para describir conductas variadas: desde el dominio del protocolo cortesano, o la actitud prudente de aquel que exhibe autocontrol y tacto en las delicadas interacciones de la alta política o de los negocios de gran envergadura, pasando por la pericia en el manejo efectivo de la servidumbre, las cualidades del gentilhombre en la conversación con sus iguales y con los miembros del otro sexo, los modales en la mesa, y más prosaicamente, la destreza en la charla inofensiva de pasillo (small talk). Para agravar la situación, ser polite también era asociado negativamente con el comportamiento maquiavélico, manipulador, hipócrita o insincero. En este contexto, la decisión de usar el término y, más aun, de defender algún sentido de la práctica a la que se refería, equivalía a intervenir en el debate acerca de la moralidad y conveniencia política de alguna de las variantes que se asociaban con esta noción. Por ello conviene aclarar que Hume discute las buenas maneras o la politeness en el limitado sentido de aquella gama de comportamientos desplegados típicamente en el escenario de la reunión social o la "conversación", mediante los cuales se muestra una deferencia o respeto especial hacia la situación, el rango, las opiniones y los sentimientos de los otros, independientemente de la verdadera evaluación de sus méritos, y con el fin de asegurar la utilidad y el agrado del encuentro social. En el siguiente pasaje, aunque sin señalar su objetivo último, Hume describe concisamente en qué consiste comportarse cortésmente o con buenas maneras:

Debemos estar dispuestos a preferir en todo momento a los demás en vez de a nosotros mismos; a tratarlos con cierta deferencia aun cuando sean nuestros iguales; a pasar, cuando estemos acompañados, por el más sencillo e ínfimo, siempre que nuestra condición no sea claramente superior a la de los demás. (T 3.2.2.12; SBN 598) $)^{4}$

4 Cito de la edición preparada y traducida por Félix Duque (Hume, 1988), siguiendo, sin embargo, el método de cita canónico para la obra de Hume. Para el Tratado de la naturaleza humana, $\mathrm{T}$ seguido del número arábico del libro, parte, sección y párrafo de acuerdo con la edición en inglés preparada por David Fate Norton y Mary J. Norton (2000), y acompañado por SBN seguido de número de página de la edición clásica preparada por L.A. Selby Bigge y complementada por P.H. Nidditch (1978). 
Es plausible, entonces, suponer que una descripción que tuviera en cuenta el resguardo de la conversación como el fin de las buenas maneras incluiría ejemplos como los siguientes: Nos comportamos con buenas maneras cuando mostramos mediante nuestros gestos y actitud que estamos escuchando atentamente aquello que nuestros interlocutores dicen; cuando respondemos, al menos como creemos que se esperaría, a los comentarios, relatos o bromas de aquellos con quienes conversamos, mediante preguntas aclaratorias, expresiones de sorpresa o simpatía, contra-ejemplos u objeciones razonables, o incluso mediante sonrisas o carcajadas si la situación parece requerirlo. También sería ejemplo del empleo de buenas maneras cuando contribuimos a la conversación, aportando nuestras propias anécdotas, explicaciones o chistes, de modo que motivemos a nuestros interlocutores a continuar con el debate. Por último, y este sería el caso paradigmático derivado del pasaje recién citado, es un rasgo claro de buenas maneras el que, mientras hacemos todo lo anterior, evitemos notar o mencionar aquellas circunstancias en la situación, el rango, las opiniones o los sentimientos de nuestros interlocutores que probablemente los incomoden porque menoscaban su estatus, su apariencia ante el grupo social o algún aspecto de su integridad.

Como puede apreciarse, las buenas maneras, en el sentido en que Hume las defiende, consisten en los rasgos de un buen y amable conversador, o quizás más precisamente, en los de un excelente anfitrión. La intención característica de tal persona consiste en promover la comodidad y esparcimiento de su invitado, dejando de lado el interés por establecer la real valía de su propia persona o de reflejar mediante su comportamiento el nivel de estima que cree que sus invitados merecen. Si bien Hume admite que las buenas maneras exigen una especie de disfraz o un ocultamiento de las propias opiniones, lo que justifica tal suerte de mentira es el mayor valor que la conversación como práctica social posee, ya que su efecto a largo plazo es el refinamiento intelectual de todos los miembros de la sociedad en un común ambiente de respeto. Por ello, el conversador antipático, sarcástico o irónico, aquel obsesionado con reafirmar su estatus o aquel que se asegura de que los demás conozcan su opinión sobre todo tema de que se trate, o 
aquel que pretende tener siempre la última palabra, no es solo desagradable sino moralmente perjudicial's.

La interpretación tradicional entre los comentaristas de Hume (Baier, 1994; Tolonen, 2008) delimita de esta forma, a mi juicio correctamente, el ámbito de las buenas maneras y entiende que el mayor obstáculo para cultivar un carácter cortés es nuestra natural tendencia a sobrevalorarnos y, en consecuencia, a exhibir ante los demás un orgullo desmedido por nuestros logros y cualidades. Debido a ello, tales autores identifican al conjunto de pasajes en los que Hume observa que no hay experiencia social más desagradable que conversar con una persona arrogante como el punto de partida de la explicación de las buenas maneras. De acuerdo con esta interpretación, Hume propone, entonces, una explicación psicológica de este fenómeno y señala a las buenas maneras como la estrategia de regulación que se ha desarrollado en sociedad para contrarrestar los efectos negativos del orgullo excesivo ( $\mathrm{T}$ 3.3.2.10; SBN 597).

Hume, en efecto, despliega un argumento apologético de las buenas maneras. La interpretación tradicional toma como una señal clara, en este sentido el hecho, de que la explicación psicológica que este autor ofrece no parte del lugar común de condenar a la pasión del orgullo, como era costumbre entre los moralistas de la época -e incluso entre nuestros contemporáneos ${ }^{6}$. En contra de la psicología cristiana, la cual había perjudicado la reputación del orgullo entendiéndolo como la actitud propia de aquel que había retado a Dios y se había declarado superior a sus congéneres, Hume lo cuenta entre las pasiones que generan disposiciones virtuosas:

La utilidad y provecho que una cualidad tiene para nosotros mismos es fuente de virtud, lo mismo que lo es su agrado para otros; la verdad es que nada

5 Nótese que en este sentido, comportamientos como los exigidos por normas de cortesía, tales como saludar y despedirse apropiadamente, o como las normas de etiqueta, los protocolos cortesanos o diplomáticos y otros formalismos similares hacen parte de las buenas maneras solo en cuanto puedan entenderse como mecanismos para facilitar el fructífero, agradable y cómodo intercambio social.

6 La desconfianza que usualmente despierta la emoción del orgullo entre los autores contemporáneos obedece al menos a dos preocupaciones. Por un lado, el orgullo produce en nosotros una mala representación de nuestro propio carácter o nos lleva a sobrevalorar nuestras cualidades (Dixon, 2005, p. 416; Richards, 1988, p. 255). Por otro lado, el orgullo tiende a hacernos imaginar que ocupamos cierta superioridad frente a los demás en el marco de, la mayoría de las veces, rebuscadas o inexistentes jerarquías (Dixon, 2005, p. 416; Hill, 1991, p. 162; Ben-Ze’ev, 1993). 
nos es más útil para conducir nuestra vida que un conveniente grado de orgullo [a due degree of pride], el cual nos hace conocer nuestro propio valor y nos da confianza y seguridad en todos nuestros proyectos y empresas. Ya puede estar dotada una persona de la cualidad que sea: a menos que se familiarice con ella y establezca proyectos apropiados a este fin, le será totalmente inútil. En todo momento es necesario conocer nuestra fuerza, y si nos estuviera permitido pasarnos por exceso o por defecto, más provechoso nos sería exagerar nuestro mérito que hacernos de él una idea inferior a su justo valor. Por lo general, la fortuna favorece a los audaces y emprendedores, y nada nos infunde mayor audacia que el tener una buena opinión de nuestra propia persona. (T 3.3.2.7; SBN 596)

Para Hume, el orgullo no es, pues, una pasión que deba ser siempre reprimida. Como se anota en este pasaje, de hecho no hay nada más útil para el individuo que sentir cierto grado de orgullo por sus propias cualidades. Aunque no siempre corresponda precisamente con la realidad, sentirnos confiados en nuestras propias cualidades nos permite desplegarlas con mayor éxito en comparación a si, desplegando humildad, dudamos de ellas. Pero, aunque el orgullo en sí mismo no es el problema, Hume tampoco cree que toda forma de experiencia o manifestación de esta pasión sea virtuosa ${ }^{7}$. Su explicación de por qué nos desagradan los arrogantes comienza con la observación de que en realidad no todas las exhibiciones de orgullo ajeno nos incomodan. Solamente nos causan desagrado las que, en palabras de Hume, son "directas". Tales expresiones son aquellas en las que el orgulloso exterioriza sin reparo frente a su audiencia la muy elevada opinión de sus logros, de sus cualidades o, en general, de sí mismo. Así pues, paradójicamente, lo desagradable del arrogante es que es demasiado sincero frente a los demás acerca de lo

7 En una nota al pie de la segunda Investigación, Hume escribe: "El término orgullo es tomado generalmente en un mal sentido; pero este sentimiento parece ser de suyo indiferente, y será bueno o malo, según esté bien o mal fundado, y según las circunstancias que lo acompańen. Los franceses expresan este sentimiento con el término amour propre; pero como también utilizan el mismo término para expresar egoísmo y vanidad, de ahí proviene la gran confusión que encontramos en Rochefoucault y en muchos otros de sus moralistas" (EPM App. 4.3n; SBN 314). Cito de la edición preparada y traducida Carlos Mellizo (Hume, 2006), siguiendo sin embargo el método de cita canónico para la obra de Hume. Para la Investigación sobre los principios de la moral, EPM seguido de sección, parte (si la hay) y párrafo de acuerdo con la edición en inglés preparada por Tom Beauchamp (2004), y acompañado por SBN seguido de número de página de la edición clásica preparada por L.A. Selby Bigge y complementada por P.H. Nidditch (1975). 
que piensa de sí. El problema es que nadie se siente cómodo frente a tanta honestidad porque la mente humana no puede evitar juzgar por contraste:

Juzgamos de los objetos más por comparación que por su mérito y valor intrínsecos (...) Pero ninguna comparación es más obvia que la que tiene por punto de referencia a nosotros mismos (...) En todas las clases de comparación, un objeto nos hace siempre obtener del otro con que es comparado una sensación opuesta a la derivada de este mismo objeto cuando es examinado directa e inmediatamente. El examen directo del placer de otra persona nos proporciona naturalmente placer; por tanto, produce dolor cuando se compara con nuestro propio placer. (T 3.3.2.5; SBN 594).

Así pues, el desagrado causado por los arrogantes es una forma de operación del principio de la naturaleza humana que Hume llama "comparación" el cual, en el caso particular, funciona de la siguiente manera: cuando percibimos la alta estima que el arrogante tiene de sí mismo, no podemos evitar compararnos con él o ella y considerar si nosotros mismos sobresalimos en aquella cualidad de la que el otro u otra se ufana. Dado que la expresión del orgullo del otro es directa, la fuerza y vivacidad que cobra en nuestra mente nos hace siempre salir mal parados de la comparación, y por ende, sentir que cuando otro se vanagloria de sí mismo nosotros nos hundimos en nuestra propia estima.

En contraste, la vanidad ajena no nos afectaría tanto, o no nos afectaría en absoluto, si las expresiones de la otra persona no fueran "directas", sino "indirectas". Es decir, si el orgulloso manifestara su placer mediante artificios que ocultaran o disfrazaran la opinión que tiene de sí mismo, nuestra percepción de su orgullo no entraría en nuestra mente con la fuerza y vivacidad necesaria para provocar aquella poco halagadora comparación entre sus logros y cualidades y los nuestros. De hecho, la expresión indirecta del orgullo ajeno puede provocar la operación del principio de simpatía: si el orgulloso es modesto es posible que nos haga experimentar vicariamente su placer, lo cual a su vez nos puede hacer sentir cierta clase de afecto hacia él o ella. En todo caso, como mínimo, el modesto nos simpatiza porque no nos enrostra la superioridad que cree poseer y así no nos hace sentir mal con nosotros mismos ${ }^{8}$.

8 No es claro si para Hume el hecho de que simpaticemos con el orgulloso en virtud de su modesta expresión es lo mismo que el que creamos que el otro está justificado en sentir el orgullo que siente. 
En la interpretación tradicional de Hume, esta última observación es la base para entender la función de las buenas maneras. Más aún, la interpretación tradicional sostiene que la virtud de la modestia es la mejor expresión de buenas maneras: el modesto logra regular la común y natural tendencia a expresar pública y abiertamente su propia sobre-estimación, y así logra comportarse como un excelente conversador ${ }^{9}$. Y es que, en efecto, una conversación entre arrogantes suele convertirse rápidamente en un enfrentamiento entre egos. Las personas modestas, por el contrario, evitan ver la conversación como un combate cuyo objetivo sea la auto-afirmación individual, y en vez de ello la ven como un ambiente de comercio en el que la rapiña y el abuso han sido eliminados y en el que se puede tratar libremente y sin recelo con los demás.

Esta última comparación entre la conversación cordial y el comercio pacífico no es azarosa. De hecho, Hume establece una reveladora analogía entre las reglas de la justicia, diseñadas para eliminar la inestabilidad de las posesiones materiales, y las reglas de las buenas maneras, diseñadas para eliminar la inestabilidad de nuestros egos:

[D]e igual modo que establecemos las leyes naturales [esto es, las reglas de la justicia] a fin de asegurar el derecho de propiedad en la sociedad e impedir la oposición entre intereses privados, establecemos también las reglas de cortesía a fin de impedir la oposición del orgullo de los hombres y hacer de la

Hume no parece reparar en este problema (T 3.2.2.6; SBN 595), pero dado que es posible que el efecto de nuestra simpatía sea contrarrestado por la creencia, adquirida independientemente, de que el orgulloso carece de la cualidad de la que indirectamente se ufana, no parece correcto entender que para Hume el agrado causado por la modesta expresión equivalga siempre a la aprobación del orgullo ajeno.

9 En este sentido, Tolonen afirma: "In the Treatise, Hume characterizes politeness as an outward principle directly related to the passion of pride. 'Good-breeding', Hume argues, requires 'that we shou'd avoid all signs and expressions, which tend directly to show' our pride (T 3.3.2.10; SBN 597). In order for everyone to be able to cultivate their pride, 'we must carry a fair outside, and have the appearance of modesty and mutual deference in all our conduct and behavior', while the actual sentiment that we nurture might be diametrically opposite to this outward sign (T 3.3.2.10; SBN 598)" (Tolonen, 2008, p. 27). Para Baier, a su vez, la modestia "is simply a recognition of the limits of one's grounds for pride" (1994, 207). De forma sugerente, Baier extiende la lectura tradicional, de acuerdo con la cual la modestia hace posible la conversación y la "compañía", y enfatiza el aspecto económico de esta virtud. Ser honesto acerca de nuestras capacidades y limitaciones frente a los demás evita la duplicación de los esfuerzos productivos y promueve la eficiente división del trabajo en la sociedad. 
conversación algo agradable e inofensivo. (T 3.2.2.10; SBN 597; en el mismo sentido EPM 8.1; SNB 261)

Según esta analogía, las reglas de las buenas maneras, así como las reglas de la justicia, buscarían regular aspectos de nuestra naturaleza que solamente atenuados hacen posible la creación de bienes comunes. Solo el auto-interés regulado hace posible los esquemas de propiedad privada que estimulan la producción de bienes materiales, mientras que únicamente el orgullo regulado hace posible esquemas de vida social que estimulan el intercambio de ideas entre individuos ilustrados (Tolonen, 2008, p. 29).

\section{Las buenas maneras y la desigualdad social}

A PESAR DE LA PLAUSibilidad de la interpretación tradicional sobre la concepción humeana de las buenas maneras, no estoy de acuerdo en su reducción de la función social de las buenas maneras a la regulación del orgullo. Si bien esta no es una interpretación irrazonable, pues es la conclusión que se sigue de la lectura del Tratado y de la Investigación de los principios de la moral, no es, sin embargo, una lectura adecuada si, como yo propongo, se toman en cuenta algunos comentarios que Hume hace sobre las buenas maneras en sus ensayos, especialmente en "Del auge y el progreso de las artes y las ciencias" (E-RP) ${ }^{10}$.

En este ensayo, Hume reconstruye los efectos sociales e institucionales que el cultivo y desarrollo de ciertas pasiones tiene en la vida de los grupos sociales. Como su título lo indica, se dedica a rastrear el desarrollo de las pasiones que motivan el surgimiento de las prácticas e instituciones que soportan las artes y las ciencias. Una de sus ideas centrales es que en una sociedad en la que se dan las condiciones para el cultivo de la pasión de la "curiosidad" suelen darse también las condiciones para el cultivo de aquel deseo que nos lleva a compartir nuestras opiniones, sentimientos y gustos con los demás. En este sentido, Hume escribe en otro de sus ensayos: "no es posible que, cuando [las naciones] están enrique-

10 Cito de la traducción al español hecha por Carlos Martín Ramírez (Hume, 2011) de la edición de los ensayos preparada por Eugene Miller (1985), siguiendo sin embargo el método de cita canónico para la obra de Hume. Para los ensayos, $E$ seguido de la abreviatura de cada ensayo establecida en Norton D., (1993), seguido por el número de página de la edición de Miller. 
cidas con la ciencia y poseen recursos de conversación, se conformen con la soledad, o vivan distantes de sus conciudadanos, a la manera que es propia de las naciones bárbaras e ignorantes" (E-RA 271) ${ }^{11}$. Según Hume, en nuestra naturaleza hay cierta relación de proporcionalidad entre el refinamiento y satisfacción de la curiosidad y el refinamiento del deseo de asociación y conversación. Esta afortunada relación de las pasiones humanas explica la naturaleza del impulso que lleva a los individuos a asociarse para la investigación intelectual o para el cultivo de las artes, y que por ende determina el carácter de las instituciones académicas y artísticas. En contraste, en sociedades conformadas por aquellos que Hume llama "bárbaros e ignorantes" no se dan las condiciones para el cultivo de la curiosidad y, por tanto, no existen ni la motivación ni las estructuras que dan origen a la arena de la conversación intelectual pública.

Sin embargo, y esta es la razón por la cual las buenas maneras son necesarias precisamente en este nivel de desarrollo del refinamiento pasional e intelectual de los grupos sociales, la conversación intelectual pública no es inmune a las desigualdades económicas, sociales o políticas inherentes al mundo no intelectual. Esto es así porque la entrada a cualquier conversación no disminuye automáticamente en sus integrantes la fuerza de algunas pasiones, originalmente presentes en la naturaleza humana, que motivan el dominio sobre los otros, el rechazo de los diferentes o el abuso de los vulnerables. De acuerdo con mi interpretación, lo que se puede concluir a partir del ensayo sobre las ciencias y las artes es que las buenas maneras son un mecanismo cuyo fin es mitigar el efecto negativo de tales pasiones en la empresa de la investigación científica y en el cultivo de las artes.

Por lo anterior, cuando en este ensayo Hume introduce su discusión sobre las buenas maneras, no se limita a repetir el punto enfatizado por la interpretación tradicional, según el cual estas regulan el orgullo desmedido. Aunque es cierto que lo menciona ${ }^{12}$, Hume también incluye en el ámbito de comportamiento polite lo que él llama una "educación refinada" (refined breeding) que nos hace conscientes y considerados frente a varios tipos de desigualdades que comúnmente surgen en el trato social. Hume ofrece cuatro ejemplos. La persona de buenas maneras es

11 "Del refinamiento de las artes".

12 En efecto, Hume reitera su punto sobre el orgullo: "para hacer la conversación y el intercambio entre las mentes más fácil y agradable se han inventado las buenas maneras” (E-RP 132). 
considerada frente a las debilidades o "achaques" (infirmities) de los ancianos y por lo tanto "redobla" sus muestras de respeto y deferencia hacia ellos. La persona de buenas maneras también es considerada frente a la especie de vulnerabilidad en la que se hallan los extranjeros, dado que se encuentran en un lugar extraño y entre extraños, y por lo tanto exhibe frente a ellos "las más altas muestras de civilidad" ("las mayores cortesías"). Tercero, cuando la persona de buenas maneras asume el papel de anfitrión, su consideración hacia el hecho de que el invitado está, en cierto sentido en sus manos, hace que asuma siempre la "más baja posición" (que se comporte como "la persona más humilde de la reunión"), en vez de imponer su voluntad y derecho como dueño de casa. Finalmente, y este es un ejemplo que refleja la época, el hombre de buenas maneras es considerado frente a la situación de inferioridad en la que se encuentran las mujeres -Hume dice por "naturaleza"- y por lo tanto se comporta hacia ellas mostrando "una deferencia y complacencia estudiadas para con todas sus inclinaciones y opiniones" (E-RP 133).

Nótese que lo que estos ejemplos muestran es que, más que la tendencia al orgullo desmedido, las buenas maneras reducen el efecto de una gama más general de tendencias humanas que nos llevan a profundizar o sacar provecho de desigualdades ya existentes en el mundo social. Así, las buenas maneras exigen una deferencia exagerada hacia los ancianos porque naturalmente los jóvenes tienden a sentir desprecio por las debilidades de aquellos. Las buenas maneras también nos exigen "las más altas muestras de civilidad" frente a los extranjeros porque la tendencia natural de los locales es a sacar provecho de la ignorancia del recién llegado. De la misma forma, las buenas maneras prescriben al anfitrión asumir "la más baja posición" porque su tendencia natural es a ver al invitado como una suerte de intruso que perturba la cotidianidad de su hogar. Finalmente, las buenas maneras exigen al hombre una cordialidad exagerada frente a las opiniones y conducta de la mujer porque nuestra tendencia natural es a perpetuar aquel sistema de instituciones que beneficia a nuestro grupo, incluso a costa de la explotación u opresión de otros. Hume expresa claramente esta idea de que las buenas maneras mitigan los efectos de la desigualdad social en los siguientes términos:

Dondequiera que la naturaleza haya hecho que la mente sea propicia a algún vicio, o a alguna pasión desagradable para los demás, la educación refinada ha enseñado a la gente a inclinar su predisposición en sentido contrario, y a 
preservar, en todo su comportamiento, la apariencia de sentimientos diferentes de aquellos a los que de manera natural tiende. (E-RP 132)

Que las buenas maneras son comportamientos artificialmente inculcados ya se insinuaba en la analogía que Hume hacía con las reglas de la justicia, pero ahora esta característica cobra su verdadera dimensión: no somos criaturas naturalmente dispuestas a respetar a los débiles, a los vulnerables o a los socialmente inferiores, menos aún cuando nuestro propio interés está de por medio. Por ello, las buenas maneras son un artificio que restringe algunas de las propensiones que nos llevan a ignorar las debilidades o necesidades de los otros y así evitan, o por lo menos contienen, el daño que les provocaríamos de otra forma:

Corregir los groseros vicios que nos llevan a infligir serio daño a otros es el cometido de la moral, y el objeto de la educación más ordinaria. Donde no se atiende a esto en algún grado no puede subsistir sociedad humana alguna. Pero, para hacer la conversación y el intercambio entre las mentes más fácil y agradable se han inventado las buenas maneras, que han llevado más lejos las cosas. (E-RP 132. Énfasis mío)

Las buenas maneras no son, entonces, una virtud de mero decoro, o un simple "lubricante" social, ni siquiera la conducta que nos imponemos con tal de poder charlar pacíficamente con nuestros pares, sino una de las virtudes que regulan los impulsos de dañar al vulnerable ${ }^{13}$.

En conexión con este carácter de las buenas maneras, Hume afirma que estas constituyen una conquista del mundo moderno introducida por la vida social cortesana ${ }^{14}$. Hume relaciona así la naturaleza de salvaguarda del débil, que en mi interpretación él entiende como central en las buenas maneras, con los ambientes sociales jerárquicos en los que las oportunidades y las tentaciones de satisfacer las pasiones contra el inferior seguramente son numerosas. La sugerencia que

13 En un sentido similar, Woodcock (2008) afirma de la virtud de la modestia: "Modesty is a valuable disposition for moral agents to possess because it alleviates some of the jealousy, bitterness and other caustic emotions that arise in social contexts where the comparative merits of agents are publicly acknowledged. It serves a delicate social function by discouraging unhealthy forms of competitive ranking, and it promotes harmony among agents who perceive themselves to be unequal with respect to their natural talents and accomplishments" (pp. 2-3).

14 En su reconstrucción del auge y progreso de las artes y las ciencias, Hume afirma que el arte de la conversación tiende a cultivarse con mayor consistencia en regímenes monárquicos (E- RP 126). 
parece desprenderse de esta relación refuerza la presente interpretación: las buenas maneras benefician más al débil que al fuerte. De allí que surjan y deban surgir precisamente en los escenarios sociales en los que las relaciones entre desiguales son la regla ${ }^{15}$.

Mi conclusión hasta este punto es entonces que, para Hume, las buenas maneras son más que un dispositivo para limitar el orgullo desmedido de aquellos que participan en una conversación refinada. Se trata, más bien, de un conjunto de reglas que buscan reducir los malos efectos de aquellas pasiones que nos llevan a aprovecharnos del débil, del vulnerable o del socialmente inferior. La utilidad de la práctica de las buenas maneras radica en que posibilita el intercambio fluido de ideas, pero no porque "lubrique" las relaciones sociales - no son simples icebreakers-, sino porque reduce la distancia social que la mayoría de las desigualdades sociales, económicas y políticas de la sociedad en la que se da la conversación trasladan a esta.

Aunque Hume desarrolla esta argumentación para el caso de la conversación refinada en el marco del "auge y progreso" moderno -siglos XVII y XVIII- de las artes y las ciencias, creo que puede ser útil para entender, si no la función que de hecho sirven, sí al menos la dirección hacia la cual pueden ser encausadas las buenas maneras en nuestro actual mundo social. En tanto entendamos por conversación todo intercambio social en el que sus participantes desean compartir y discutir libremente las opiniones y sentimientos de los otros, ya fuere por el mero agrado de hacerlo, por el agrado más complejo de dejar la conversación con opiniones o sentimientos más sólidos ${ }^{16}$, o incluso con el objetivo de acordar cursos futuros de acción, creo que es acertado afirmar, como lo hace Hume, que cierta

15 En este sentido, en una monarquía, dice Hume, un "candidato para un cargo (...) tiene que dirigir su atención hacia arriba, para granjearse la gracia y el favor de los grandes" de modo que "[p]ara prosperar (...) tiene que hacerse grato gracias a su ingenio, complacencia o [civilidad]" (E-RP 126. Cursivas mías). Nótese, sin embargo, que este pasaje sugiere una ambivalencia reveladora de la consideración de las buenas maneras propia de la época: las buenas maneras son en realidad una forma de hipocresía mediante la que el débil o inferior se congracia con el fuerte o superior y así obtiene mejoras en su posición. Esta ambivalencia es en el fondo más profunda: toda defensa de las buenas maneras, ya sea como ventaja del grupo social privilegiado o como mecanismo de protección del débil, se mantiene siempre cerca de ser una defensa de la apariencia, de la duplicidad y, en cierta forma, de la mentira. Al respecto, ver Davidson (2004).

16 Como anota Jonathan Swift: "The two chief ends of conversation are, to entertain and improve those we are among, or to receive those benefits ourselves" (2001, p. 3). 
dosis de buenas maneras protege la dinámica propia de la conversación de desigualdades perjudiciales entre los conversadores. Esta es una moraleja importante porque no solo conversamos en ambientes informales con nuestros amigos también es una forma de conversación aquella que sostenemos con profesores o estudiantes en los salones de clase, con los directivos de nuestras instituciones en las salas de reuniones, o con los políticos que gobiernan las prácticas académicas y de investigación. En todos esos escenarios, las buenas maneras podrían verse como dispositivos de negociación del poder, los cuales capitalizan el interés que todo sujeto con autoridad tiene de aparecer bien en público para nivelar el campo de juego en favor del débil, del vulnerable o del socialmente inferior.

\section{Buenas maneras e inclusión social: ambivalencia y límites}

A PESAR DEL FAVOR que muestra por las buenas maneras, Hume no ignora el hecho de que ellas no eliminan las pasiones contra el débil, el vulnerable o el socialmente inferior. Como algunos pasajes citados anteriormente indican, las buenas maneras no pueden exigir más que una "apariencia" de respeto hacia quienes de otra forma dominaríamos o explotaríamos. Este rasgo de las buenas maneras fue el obvio flanco de ataque de quienes cuestionaban su moralidad: parece haber muy poca diferencia entre ser cortés y ser hipócrita ${ }^{17}$. Esta objeción arroja una sombra de duda sobre el supuesto carácter virtuoso de la persona con buenas maneras. Quizás no sea realmente cortés, sino condescendiente o, en todo caso, insincero.

Pero nótese que una de las consecuencias de la analogía que Hume establece entre las reglas de la justicia y las reglas de las buenas maneras es que la utilidad de ambas depende más de que los participantes de hecho las sigan y menos de la intención o el motivo último que pueda tener cada uno de ellos para hacerlo. Así pues, la réplica al cargo de hipocresía de las buenas maneras es que poco importa que lo sean. El beneficio de las buenas maneras en cuanto práctica se da con independencia de las intenciones de sus participantes. En un sentido, al menos cierta clase de hipocresía es útil, y en todo caso, solo alguien realmente ingenuo

17 Este ataque moral a las buenas maneras fue dirigido entre otros por Shaftesbury (1711), Wollstonecraft (1792) y Godwin (1793). 
tomaría las cortesías que recibe como sinceras muestras de afecto por parte de su interlocutor. Como expresa Hume:

No creo que nadie con un poco de mundo y de penetración en los sentimientos íntimos de los hombres sostenga que la humildad exigida por la buena educación y el recato deba ser algo más que el mero guardar las formas, o que considere como parte integrante de nuestro deber el que seamos absolutamente sinceros en este punto. (T 3.2.2.12; SNB 598) ${ }^{18}$

Pero la sospecha que conecta las buenas maneras con la hipocresía adquiere una seriedad diferente si se la mira desde otro ángulo. Si se tienen en cuenta las relaciones entre buenas maneras y civilización que todos los defensores de aquellas se empeñaban en resaltar, la crítica se torna política y directamente aplicable a la apología desarrollada por Hume. El problema es que en el fondo las buenas maneras son excluyentes. En vez de proteger al débil, al vulnerable o al socialmente inferior, las buenas maneras lo aíslan y lo ponen aún más a merced de la opresión. El ejemplo más claro y radical de esta crítica es el de Rousseau, quien siguiendo una línea de argumentación nada descabellada, vincula las costumbres civilizadas del mundo moderno con sus desigualdades políticas y económicas, invirtiendo así, por completo, la propuesta humeana. El problema que señala esta clase de crítica no tiene que ver tanto con la moralidad del despliegue de instancias particulares de buenas maneras, ni con la genuina virtud moral de la persona cortés o polite, sino con la posibilidad de que las buenas maneras sean usadas como dispositivos de conservación de las estructuras de poder que mantienen a ciertos grupos sociales al margen de los recursos materiales y culturales que estos mismos grupos son obligados a producir.

18 En general, Hume no otorga un lugar moralmente privilegiado a la verdad o a la sinceridad, como lo hacen William Godwin o Emanuel Kant. Hume considera la sinceridad más como un privilegio del que disfrutan cierta clase de relaciones, que como un deber al que todo individuo esté sujeto. En una carta dirigida a un amigo en abril de 1764, Hume escribe: "Did ever one make it a point of Honour to speak Truth to Children or Madmen?” (Citado por Davidson, 2004, p. 95). En varios puntos, la defensa humeana de las buenas maneras puede entenderse como una defensa de la utilidad de la hipocresía. Más aún, es interesante que para Hume el argumento en favor de las buenas maneras parece la otra cara de la moneda de su argumento en contra de las supersticiones de la religión católica: aunque ambas implican una serie de rituales que ninguna persona razonable reconocería como dotados con poderes causales, los de las buenas maneras deben admitirse en razón de su utilidad para el intercambio social, mientras que los de la religión católica deben rechazarse en virtud de que no producen ningún beneficio, y en cambio, fortalecen el dominio de los clérigos. 
Una de las formas en que las buenas maneras manifiestan tal naturaleza excluyente es cuando son usadas para distinguir la clase social a la cual pertenece un individuo con el fin de limitar su acceso a determinados recursos. Así no es inusual ver cómo las maneras que una persona exhibe en su presentación ante los demás son usadas para juzgar su origen, su educación, sus contactos sociales, etc., y con base en ello es, o bien excluida del grupo, o bien convertida en objeto de explotación, discriminación, burla o abuso.

Permítaseme un paréntesis para apuntar que, paradójicamente, tal uso excluyente de las buenas maneras no está libre de tensiones para los grupos privilegiados. Uno de los puntos de debate más constantes que sobre las buenas maneras se dieron durante el siglo XVII giró en torno a la forma en que ellas constituían una especie de capital cultural de la clase privilegiada que, sin embargo, podía ser usurpado por las clases subalternas y usado en su contra. Esta preocupación se nota, por ejemplo, en algunas de las sátiras de Jonathan Swift, las cuales constituyen el ejemplo perfecto del llamado "problema de la servidumbre" "the servant problem”, Davidson, 2004, p. 15). Este problema consistía en que, a los ojos del mundo social en el que se movía la clase privilegiada inglesa, el decoro y prestigio que mostrara la servidumbre se reflejaba para bien o para mal en la reputación del señor. Por esta razón, las buenas maneras eran parte integral del entrenamiento que recibía la clase subalterna, a tal punto que el objetivo no declarado consistía en convertirlos en copias con librea de sus superiores. No obstante, la clase privilegiada sabía muy bien que la clave para dominar las costumbres corteses era una excepcional destreza en la apariencia y la duplicidad. Y esto era la fuente de su gran ansiedad, pues sentían que la servidumbre podía usar aquellas habilidades para apoderarse de sus bienes, para extorsionarlos o, peor aún, para casarse o escaparse con sus hijas. Esta ambivalente preocupación por refinar a la servidumbre al tiempo que se quería mantener a las buenas maneras como privilegio exclusivo de la clase alta atraviesa, por ejemplo, el argumento de Bernard Mandeville en contra de impartir educación a los pobres, expuesto en Un ensayo sobre la caridady las escuelas de caridad (An Essay on Charity and Charity Schools, 1714), y las constantes recomendaciones de John Locke en Pensamientos acerca de la educación (Some Thoughts Concerning Education, 1693) de mantener a los hijos lo más alejados posible de la servidumbre. 
Volviendo al argumento, otra forma en que las buenas maneras son utilizadas como recurso de exclusión se manifiesta en el establecimiento de tipos diferenciados de buenas maneras de acuerdo con el género del grupo social. El ejemplo más claro, y que Hume elabora siguiendo el consenso de su época, es el de las "virtudes femeninas". La modestia y la castidad eran la modalidad de buenas maneras impuesta diferencialmente a las mujeres y que regulaba el modo en que ellas presentaban su cuerpo, pero también sus opiniones y sentimientos, en el mundo público dominado por los hombres. Según la explicación de Hume, la necesidad de esta forma de buenas maneras surge de la circunstancia de que, en ausencia de una confiable capacidad técnica para establecer la paternidad de sus hijos, los hombres necesitan contar con la seguridad de que aquellos niños cuya crianza costean sean realmente los suyos. Dado el ímpetu del deseo sexual, tanto de hombres como de mujeres, no basta con la promesa o la palabra de la madre, sino que es preciso regular el acceso sexual de todo hombre a toda mujer y solo permitirlo al esposo. La modestia y la castidad exigidas a las mujeres son la manera más efectiva posible de regular tal acceso, pues imponen la regulación en la propia fuente:

¿Qué restricción impondremos entonces a las mujeres para contrarrestar una tentación tan fuerte como la que tienen por la infidelidad? No parece que sea posible otra restricción sino la de castigarlas por medio de la mala fama o reputación; en efecto, este castigo ejerce una poderosa influencia sobre la mente humana (...) A fin de obligar, pues al sexo femenino a guardar la debida compostura unimos a su infidelidad un peculiar grado de infamia, superior al originado meramente por lo inmoral de la falta; (...) del mismo modo alabamos a la mujer por su castidad. (T 3.2.12.4; SBN- 571)

Así pues, la modestia y la castidad imponían una carga desigual sobre las mujeres, en comparación con la de los hombres, y son ejemplo, de esta forma, del carácter excluyente que las buenas maneras pueden adoptar. $Y$ es que en general lo que este par de ejemplos muestran es que las buenas maneras son instrumentos en cuya definición se juega muchas veces el reparto del poder entre diferentes grupos sociales. Por ello, quién determina y qué cuenta como buenas maneras son en realidad cuestiones que rodean las dinámicas de la conquista y dominio del espacio social.

Una forma de interpretar la naturaleza del argumento humeano en favor de las buenas maneras reconstruido en la sección anterior es como el intento de este autor de alterar las relaciones de poder entre algunos de los diferentes grupos 
sociales de la Inglaterra y Escocia de su época. Hume parece, en efecto, querer reapropiarse de las buenas maneras en favor de, por un lado, la emergente clase media burgués y, por el otro, la población femenina de esa misma clase social. La idea de que las buenas maneras son mecanismos de protección del débil, del vulnerable o del socialmente inferior, apunta a inscribir a las buenas maneras en el ámbito de una moralidad guiada por el principio de humanidad, el cual, a su vez, constituye la versión filosófica que recoge valores como la solidaridad y la benevolencia, propios del naciente mundo mercantil de entonces. En tal sentido, Hume busca desligar a las buenas maneras de su origen en las prácticas caballerescas (chivalry), las cuales se estructuraban en torno al honor y la jerarquía respaldados por la organización del poder feudal o, simplemente, por la fuerza bruta.

El intento humeano de re-apropiarse de las buenas maneras en favor del sector femenino de la clase media se encuentra en su tratamiento de la "galantería". La galantería era la especie de las buenas maneras que imponía al gentilhombre un trato cortés hacia aquellas mujeres con quienes pretendía establecer comercio se$\mathrm{xual}^{19}$. Dadas las especiales relaciones de poder existentes entre los géneros, la galantería en realidad servía como una forma de imposición del dominio de un sexo sobre el otro. Para sus críticos, la galantería no era más que un eufemismo autocomplaciente de lo que debería llamarse simplemente promiscuidad o adulterio. Hume, sin embargo, intenta inscribir la galantería dentro de su proyecto apologético de las buenas maneras. El resultado es instructivo tanto del poder incluyente de estas, como de sus límites. Por ello vale la pena analizarlo a continuación.

En cierto punto del ensayo "Del auge y el progreso de las artes y las ciencias", Hume introduce, para enfrentarla, la crítica shaftesburiana según la cual toda forma de buenas maneras degenera en una conducta "afectada y ridícula" $(\mathrm{E}-\mathrm{RP} 131)^{20}$. Hume escoge, entonces, a la virtud de la galantería para hacer frente a esta crítica.

19 Hume no es original en entender a la galantería como una especie de las buenas maneras. La galantería, en efecto, había sido tradicionalmente tomada como la manifestación de las buenas maneras en el ámbito de las relaciones románticas entre hombre y mujer (Davidson, 2004).

20 El original inglés es más extenso en la descalificación. Las buenas maneras son "affectation and foppery, disguise and insincerity". 
Seguramente fue una sorpresa para sus contemporáneos lectores que Hume recurriera a una de las formas más vituperadas de las buenas maneras para defender el poder igualador y civilizatorio de la práctica como un todo. Tan extraña era esta estrategia que unos años más tarde Mary Wollstonecraft tomará precisamente a la galantería como el foco de su ataque contra la dominación de la que son víctimas las mujeres en su Vindication of the Rights of Women (1792), pese a sus coincidencias con varias de las ideas de Hume. En todo caso, según Hume, la galantería es el mejor ejemplo de la forma en que las buenas maneras pueden servir a la inclusión de un grupo social tradicionalmente excluido.

Como toda otra forma de relación que pueda ser regulada por las buenas maneras, la galantería supone un afecto natural, en este caso, el "afecto entre los sexos", el "mejor y más dulce disfrute (...) en todas las especies de animales". Pero, aunque los animales humanos son capaces de experimentar esta afección como lo hace cualquier otro animal, debido a que somos criaturas racionales, también podemos experimentarla junto con la "pasión amorosa". Cuando esto sucede, el impulso producido por la unión de ambas afecciones no se satisface con la mera gratificación del deseo corporal. Las relaciones románticas propiamente humanas requieren de "la razón, el discurso, la simpatía, la amistad y la alegría" (E-RP 134) entre las partes para ser verdaderamente satisfactorias. De este modo, Hume redefine a la galantería como el conjunto de reglas sociales que maximizan las oportunidades de obtener tales refinados placeres de una relación romántica, en claro contraste con el juicio común de la época.

Y es que quizás muy pocos caballeros de tiempos de Hume ejercían su galantería de acuerdo con esta descripción. Pero precisamente en torno a esto gira su estrategia argumentativa. El argumento concede que el motivo que impulsa a la galantería es decididamente auto-interesado, pero la satisfacción de tal auto-interés, por su propia naturaleza, supone Hume, implica una forma de comercio con la mente del otro que poco a poco excluye el ejercicio abusivo del poder. Por esta razón Hume no oculta el hecho de que la galantería tiene como base la política de las relaciones entre los sexos:

Como la naturaleza ha otorgado al hombre la superioridad sobre la mujer, dotándole de mayor fuerza tanto de la mente como del cuerpo, es su obligación aliviar esa superioridad, en la medida de lo posible, mediante una deferencia y complacencia estudiadas para con todas sus inclinaciones y 
opiniones. Las naciones bárbaras muestran esa superioridad reduciendo a sus mujeres a la más abyecta esclavitud, confinándolas, vendiéndolas, matándolas. (E RP 133)

Ignorando el prejuicio de la época, según el cual el hombre es naturalmente superior a la mujer, lo que me importa resaltar de esta afirmación es la idea de que lo distintivo de la galantería, en contraste con las costumbres bárbaras, radica en aliviar el peso de la supuesta diferencia de poder entre los sexos. Esta tesis se evidencia mejor en la galantería que en cualquier otra forma de buenas maneras, razón por la cual Hume la escoge para enfrentar la crítica del carácter excluyente de las buenas maneras. De hecho, la efectividad de la galantería depende, más que la de cualquier otra forma de buenas maneras, de que el fin que buscan sus participantes mediante la práctica de las reglas coincida con el fin de las reglas mismas. La interacción cuidadosamente regulada, que la galantería exige a ambas partes en la construcción y cultivo de la relación, busca movilizar las afecciones necesarias para lograr la simpatía y la alegre amistad que un genuino e íntimo comercio de mentes supone.

Uno de los aspectos más interesantes de esta concepción de la galantería es que, para Hume, el genuino e íntimo comercio de mentes que esta práctica promete no solamente tiene como beneficioso efecto la satisfacción de la pasión amorosa de los enamorados. Hume señala que la interacción con el otro género "refina la mente del hombre" y que esto se nota no solamente en el tipo de relación que los hombres construyen con las mujeres, sino en el tipo de relación que cualquiera de ellos construye con cualquier otro miembro de la sociedad:

¿Qué mejor escuela de modales que la compañía de mujeres virtuosas, donde el mutuo esfuerzo por complacer tiene insensiblemente que pulir la mente, donde el ejemplo de la suavidad y modestia femeninas tiene que comunicarse a sus admiradores, y donde la delicadeza de ese sexo pone a todos en guardia, no vaya a ser que incurran en ofensa quebrantando la decencia? (E-RP 134)

Debido a esta característica de la galantería es que Hume anticipa al comienzo de su argumento, que ella es una de las causas del refinamiento de las costumbres del mundo moderno: "Si se concediera a los tiempos modernos la superioridad en la cortesía, probablemente se atribuirían las causas de este refinamiento a los modernos conceptos de la galantería" (E-RP 131). La idea aquí parece ser que la galantería causa el refinamiento general de las costumbres porque 
incluye a las mujeres en el mundo de la conversación intelectual refinada de los hombres. La galantería logra esto porque una vez que los hombres la practican y entran en verdadero intercambio con las opiniones y sentimientos de las mujeres no pueden evitar reconocer en ellas a sus pares intelectuales. De esta forma, la galantería convierte las diferencias que inicialmente se presentan como barreras que separan a los dos géneros en atractivos puntos de vista contra los que vale la pena discutir los propios. En otras palabras, la galantería permite refinar las cualidades de ambas partes porque es una forma de inclusión de un grupo social ${ }^{21}$.

Lo original en esta estrategia humeana radica en tomar aquella forma de las buenas maneras que era comúnmente practicada para instrumentalizar a las mujeres y re-interpretarla como una forma de inclusión en su favor ${ }^{22}$. Es evidente que el modelo de relación romántica que Hume tiene en mente es de carácter heterosexual y monógamo. No obstante, para efectos de mi argumento, lo que importa es la idea de que las buenas maneras promueven el comercio de mentes entre miembros de grupos que tradicionalmente se consideran separados por barreras difíciles de superar. La usual oposición entre los dos géneros es uno de esos casos, pero la idea puede extenderse a otras oposiciones entre grupos sociales.

21 La creencia de que incluir a las mujeres en el mundo de la conversación es beneficioso para la formación del carácter de los hombres, y por esta ruta, que es una inclusión civilizadora no es original de Hume. Jonathan Swift, termómetro cultural de la época, también expresaba este mismo punto en los siguientes términos: "This degeneracy of conversation, with the pernicious consequences thereof upon our humours and dispositions, hath been owing, among other causes, to the custom arisen, for some time past, of excluding women from any share in our society, further than in parties at play, or dancing, or in the pursuit of an amour. I take the highest period of politeness in England (and it is of the same date in France) to have been the peaceable part of King Charles I.'s reign; (...) the methods then used for raising and cultivating conversation were altogether different from ours; several ladies, whom we find celebrated by the poets of that age, had assemblies at their houses, where persons of the best understanding, and of both sexes, met to pass the evenings in discoursing upon whatever agreeable subjects were occasionally started; (...) I conceive their refinements were grounded upon reason, and that a little grain of the romance is no ill ingredient to preserve and exalt the dignity of human nature, without which it is apt to degenerate into everything that is sordid, vicious, and low. If there were no other use in the conversation of ladies, it is sufficient that it would lay a restraint upon those odious topics of immodesty and indecencies, into which the rudeness of our northern genius is so apt to fall" (Swift, 2001, p. 5).

22 Lo cual, de hecho, puede entenderse como una descripción del uso que realmente le dieron las mujeres a la atención que recibían por parte de los hombres galantes. Convertidas en centro de la galante atención masculina, en principio como simples objetos de deseo sexual, se convirtieron poco a poco en el legislador de las buenas costumbres, y lograron monopolizar la autoría de los libros de conducta en la Inglaterra del siglo XVIII. 
Ahora bien, este encomiable intento humeano por rescatar a las buenas maneras se apoya en dos supuestos, cuyo examen revela los límites del argumento. En primer lugar, Hume acepta que el ejercicio de las buenas maneras exige una gran dosis de apariencia, artificio o, incluso, insinceridad. Ya se ha dicho que esto no representaba una poderosa preocupación a los ojos de Hume pues, por un lado, nadie resulta engañado con los actos de cortesía y, por el otro, se trata de artificios socialmente beneficiosos. Detrás de este par de razones, no obstante, existía una creencia común que resurgía casi sin falta en los argumentos usados durante la época para defender la utilidad de la cortesía: debido a la fuerza del hábito, las buenas maneras llegan de hecho a engendrar sentimientos sinceros en favor de aquellos con quienes al comienzo nos comportamos cortésmente solo por apariencia ${ }^{23}$. Hume deja ver su fe en este lugar común en un famoso pasaje al inicio de su discusión sobre la convención de la justicia:

Cuando un motivo o principio de virtud es común a la naturaleza humana, la persona que siente faltar en su corazón ese motivo puede odiarse a sí misma por ello y realizar la acción sin la existencia del motivo, basándose en un cierto sentido del deber y con la intención de adquirir con la práctica ese principio virtuoso. (T 3.2.1.8; SBN 479)

Es muy probable que al menos una parte de la esperanza que Hume depositaba en el poder civilizatorio de las buenas maneras radicara en la confianza que compartía con otros autores de su tiempo en esta versión del patrón psicológico que hoy resumiríamos en la frase "fake it 'till you make it". Confiar en que un hombre que al comienzo galantea con mujeres solo por interés sexual, se convierta luego en el más sincero de los admiradores del sexo femenino únicamente tiene sentido gracias a esa fe en la fuerza del hábito. El problema, dejando aparte la plausibilidad psicológica de la cuestión, es que al menos históricamente la confianza en que repetir la apariencia crea la realidad tuvo efectos contradictorios. Hacia finales del siglo XVII y comienzos del XVIII, el Reino Unido experimentó un incremento sin precedentes en la publicación de libros de conducta, algo así como los manuales de buenas maneras o lo que nosotros conocemos como

23 Samuel Johnson, el gran periodista y modelo de gentilhombre de la época, escribía en el periódico The Rambler: "even [the hypocrite] might be taught the excellency of virtue, by the necessity of seeming virtuous" (Citado por Davidson, 2004, p. 96). 
manuales de urbanidad y etiqueta. Debido a que estos libros por su propia naturaleza enseñaban a aparecer y mostrarse como si uno tuviera los mejores sentimientos ante los demás, su efecto fue que sus lectores naturalmente se enfocaron más en la apariencia de la virtud que en la virtud misma. Las buenas maneras se convirtieron, precisa y paradójicamente en virtud de esta abierta propaganda en su favor, en aquello que temían sus más feroces críticos: en ocasiones para la insinceridad y la hipocresía que obstaculizaban la búsqueda de un genuino reconocimiento social y político para los excluidos.

El segundo supuesto que respaldaba la defensa de las buenas maneras era la existencia de una sociedad marcada por una fuerte tendencia hacia la igualdad, o al menos, hacia una cultura en la que el nacimiento no determinaba férreamente la posición social, política o económica. En efecto, Hume desarrolla una forma de defender las buenas maneras que parte de supuestos y propósitos diferentes a la forma en que, por ejemplo, Edmund Burke las defendía. En su implacable crítica a los revolucionarios franceses, Burke, entre otras cosas, los acusa de carecer de buenas maneras. Esta no era para él una acusación de poca importancia. El punto de Burke es que los revolucionarios franceses carecen del respeto apropiado hacia la tradición y sus jerarquías, el cual es imprescindible para el orden social. Los revolucionarios, al negarse a reconocer la debida pleitesía al rey o el valor de los títulos cortesanos, amenazan la estructura política y social que mantiene unida a la comunidad. Para Burke, por tanto, la obediencia a una forma específica de buenas maneras - una forma asentada en las jerarquías propias de la monarquía inglesaequivale a la obediencia a las reglas que dan forma a la sociedad como un todo. En contraste, cuando Hume defiende las buenas maneras, lo hace pensando en la clase de cortesías que los gentiles hombres de la clase media comercial de Inglaterra se mostraban entre sí y a las galanterías que regalaban a sus mujeres. Esta es una especie de buenas maneras que tiene lugar, por tanto, en un contexto de relativa igualdad social, política y económica. Sin ese contexto de igualdad, el efecto nivelador de las buenas maneras pierde considerable fuerza. Quizás, la moraleja más prudente que se puede extraer de la apología humeana de las buenas maneras es que, aunque estas no producen instituciones ni personas justas, sí constituyen un saludable ejercicio que mantiene en buena forma moral a tal tipo de individuos y que quizás, a la larga, redunda en el ambiente social. 
Por lo anterior, el argumento humeano debe leerse con cierta reserva: la moralidad de las buenas maneras supone la moralidad de la estructura social en las que se dan. Es posible, entonces, que se den comunidades en las que las buenas maneras reflejan la injusticia y la corrupción de estructuras más profundas. No debemos suponer que siempre es moralmente debido o aceptable comportarse cortésmente, o mejor dicho, debemos reflexionar siempre acerca de las consecuencias de comportarse con buenas maneras. Así como hace algunos años, Marilyn Frye (2000) reflexionaba sobre el poder opresivo que el hombre ejerce sobre la mujer cada vez que le abre la puerta en aparente acto de caballerosidad, debemos considerar el poder que se juega en las cortesías que nos regalamos a diario, en especial, las cortesías que mostramos para con aquellos que visiblemente ostentan el poder.

\section{Las buenas maneras en el oficio del filósofo}

A MODO DE CONCLUSIÓN, quiero señalar algunas lecciones útiles del debate sobre las buenas maneras para el oficio del filósofo y del historiador de la filosofía. Quizás la mejor manera de presentar esta idea es mediante una analogía: de la misma forma en que comportarse cortésmente con los desiguales tiene la función moral de propiciar la disminución de la distancia social, y en ocasiones la completa eliminación de esta, hay una especie de cortesía interpretativa que prescribe al filósofo y al historiador de la filosofía esforzarse por superar la distancia moral e intelectual que los separa de otros filósofos y filósofas, algunos de ellos filósofos y filósofas del pasado.

Solo tengo tiempo para elaborar esta idea mediante un corto ejemplo. Hay una nueva tendencia en el estudio de la historia de la filosofía moderna que, a mi juicio, sirve para ilustrar la clase de cortesía intelectual a la que quiero invitarlos. A partir de la serie de reflexiones que sobre el método en la historia de la filosofía iniciaron Richard Rorty, Quentin Skinner y Jerome Schneewind en la década de los ochenta (Rorty et al., 1984), filósofas de la siguiente generación introdujeron la cuestión acerca de quiénes y cómo se construye el canon filosófico ${ }^{24}$ : es decir,

24 Entre ellas, vale la pena resaltar el trabajo de Annete Baier, Lisa Shapiro, Robin May Scott, Jacqueline Broad, Ruth Hagengruber, Sarah Hutton, Andreas Blank. 
quién y cómo la lista de individuos y autores que a lo largo de la historia se reconocen como "filósofos". Este grupo de filósofas llaman la atención acerca de lo poco azaroso que es el hecho de que el canon filosófico esté conformado por un grupo reducido de hombres europeos provenientes de clases privilegiadas. El objetivo no es simplemente que reconozcamos lo socialmente selectivo que era el acceso a la práctica filosófica en el pasado, sino que tomemos conciencia de que continuar estudiando filosofía asumiendo que solo las voces de tales personajes ostentan autoridad filosófica, cohíbe desde su formación la existencia de otras voces en nuestro presente. No debemos asumir con respecto a ningún filósofo que existe una equivalencia entre su calidad filosófica y su antigüedad en el canon, así como no debemos asumir con respecto a ninguna persona que existe una equivalencia entre su probidad moral y la posición que ocupa en la jerarquía social.

Qué entra o sale del canon filosófico es determinado por las decisiones editoriales sobre qué libros o artículos de revista publicar, las decisiones políticas sobre qué clase de investigaciones académicas financiar, las decisiones administrativas sobre qué académicos contratar, las decisiones intra-institucionales sobre qué temas se deben incluir en los currículos universitarios, o qué cursos se deben ofrecer en la planeación de las programaciones semestrales. La diferencia entre un canon filosófico excluyente y uno que no lo sea se juega en esta clase de decisiones, las cuales no siempre tienen que ver con aspectos estrictamente filosóficos. Entonces, es moralmente relevante que editores, políticos, administradores y nosotros mismos al solicitar, planear y ofrecer nuestros cursos mostremos buenas maneras, nos dejemos de escudar en la fama, no siempre justamente ganada, del autor o tema clásicos y, al menos, aparentemos promover un mejor ambiente moral en la práctica de la filosofía. Recordemos: la mejor descripción de la persona con buenas maneras es la del excelente anfitrión, aquel que pone la integridad de las personas sobre la verdad de las opiniones.

Con esto último, no quiero invertir la expresión, atribuida a Aristóteles, según la cual "Soy amigo de Platón, pero más amigo de la verdad" (Amicus Plato sed magis amica veritas). De hecho, abrir el canon filosófico a la inclusión de autores poco reconocidos ha producido una revitalización y sofisticación sin precedentes en la investigación de la historia de la filosofía moderna. Recientes estudios en la filosofía de Malebranche (Nadler, Schmaltz), Gassendi (Lolordo, Fisher), Newton (Downing, Janiak), los Platónicos de Cambridge y Reid (Copenhaver, Lehrer, Van 
Cleve) han permitido entender mejor el contexto intelectual de la época y, de ese modo, ubicar con mucha más precisión la originalidad del aporte de las usuales figuras prominentes. Otros, en torno al trabajo de Mary Astell, Lady Marsham y Mary Wollstonecraft, han permitido comprender el activo papel que las mujeres filósofas jugaron en el desarrollo del pensamiento de la edad moderna. Creo que no es extraño que tal inclusión haya favorecido la calidad de los resultados de la investigación en la historia de la filosofía. En últimas, las buenas maneras, como todas las virtudes en la filosofía moral de Hume, son medios, esto es, comportamientos que tienen como finalidad la mejor y más completa satisfacción de nuestras pasiones. Las buenas maneras en el ámbito académico constituyen una virtud porque son medios para satisfacer mejor y más completamente nuestra curiosidad.

\section{Referencias}

Baier, A. (1994). A Progress of Sentiments: Reflections on Hume's Treatise. Cambridge: Harvard University Press.

Ben-Ze'ev, A. (1993). The Virtue of Modesty. American Philosophical Quarterly, 30(3), pp. 235-246.

Davidson, J. (2004). Hypocrisy and the Politics of Politeness. Manners and Morals from Locke to Austen. New York: Cambridge University Press.

Dixon, N. (2005). Modesty, Snobbery and Pride. The Journal of Value Inquiry, 39 , pp. 415-429.

Driver ,J. (1989). The Virtues of Ignorance. Journal of Philosophy, 86,(7), pp. 373-384.

Frye, M. (2000), Oppression. A. Minas (Ed.), Gender Basics: Feminist Perspectives on Women and Men (pp. 10-16). Wadsworth: Wadsworth Press.

Godwin, W., (1793). An Enquiry Concerning Political Justice, and its Influence on General Virtue and Happiness. London: G.G.J. and J. Robinson. 2 vols. Disponible en línea: http://oll.libertyfund.org/titles/169 Recuperado: 13.01.16

Hill Jr., T.E. (1991). Social Snobbery and Human Dignity. Autonomy and SelfRespect. Cambridge: Cambridge University Press. 
Hume, D. (1978). A Treatise of Human Nature. L.A. Selby-Bigge \& P.H. Nidditch (Eds.). Oxford: Oxford University Press.

Hume, D. (1987). Essays. Moral, Political and Literary. E. F. Miller (Ed.). Indianapolis: Liberty Fund.

Hume, D. (1988). Tratado de la naturaleza humana. Madrid: Tecnos.

Hume, D. (1990). Disertación sobre las pasiones. Madrid: Editorial Ánthropos.

Hume, D. (2000). A Treatise of Human Nature. D. Norton \& M. Norton (Eds.). Oxford: Oxford University Press.

Hume, D. (2001). Investigación sobre el conocimiento humano. Madrid: Editorial Alianza.

Hume, D. (2004). Enquiry concerning the Principles of Morals. T.L. Beauchamp (Ed.). Oxford: Oxford University Press.

Hume, D. (2005). Enquiries concerning Human Understanding and concerning the Principles of Morals. L.A. Selby-Bigge \& P.H. Nidditch (Eds.). Oxford: Oxford University Press.

Hume, D. (2006). Investigación sobre los principios de la moral. Madrid: Editorial Alianza.

Hume, D. (2011). Ensayos morales, politicos y literarios. Madrid: Trotta.

Klein, L. (1994). Shaftesbury and the Culture of Politeness. Moral Discourse and Cultural Politics in the Early Eighteenth-Century England. New York: Cambridge University Press.

Locke, J. ([1693] 1884). Pensamientos acerca de la educación. Madrid: La Lectura.

Mandeville, B. ([1714] 1988). The Fable of the Bees or Private Vices, Publick Benefit. 2 vols. Indianapolis: Liberty Fund. Disponible en línea: http://oll.libertyfund.org/title/846

Richards, N. (1988). Is Humility a Virtue? American Philosophical Quarterly, 25(3), pp. 253-259.

Rorty, R.; Skinner, Q. \& Schneewind, J. (Eds.). (1984). Philosophy in History. Essays on the Historiography of Philosophy. Cambridge: Cambridge University Press.

Shaftesbury III Earl. ([1711] 2000). Characteristics of Men, Manners, Opinions, Times. E.K. Lawrence (Ed.). Cambridge: Cambridge University Press. 
Schueler, G.F. (1997). Why Modesty Is a Virtue. Ethics, 107, pp. 467-485.

Swift, J. (2001). Hints Towards an Essay on Conversation. Disponible en línea: http://www.blackmask.com Recuperado:12.01.16.

Tolonen, N. (2008). Politeness, Paris and the Treatise. Hume Studies, 34(1), pp. 21-42.

Waldron, J. (1988). When Justice Replaces Affection: The Need for Rights. Harvard Journal of Law and Public Policy, 11, pp. 625-642.

Waldron, J. (2013). Civility and Formality. New York University School of Law Public Law and Legal Theory Research Public Series. Working Paper, 13-57.

Wollstonecraft, M. (1792). A Vindication of the Rights of Woman. Indianapolis: Liberty Fund. Disponible en línea: http://oll.libertyfund.org/titles/2513 Recuperado: 13.01.16.

Woodcock, S. (2008). The Social Dimensions of Modesty. Canadian Journal of Philosophy, 38, pp. 1-29. 